\title{
Commentary: What makes a cardiac surgical intensive care unit safe after midnight?
}

\author{
Leila Hosseinian, MD, ${ }^{\mathrm{a}}$ and David L. Reich, $\mathrm{MD}^{\mathrm{a}, \mathrm{b}}$
}

\footnotetext{
From the a Department of Anesthesiology, Perioperative, and Pain Medicine, Icahn School of Medicine at Mount Sinai, New York; and ${ }^{\mathrm{b}}$ The Mount Sinai Hospital, New York, NY.

Disclosures: Authors have nothing to disclose with regard to commercial support.

Received for publication Sept 21, 2018; accepted for publication Sept 21, 2018; available ahead of print Nov 15 , 2018.

Address for reprints: David L. Reich, MD, Horace W. Goldsmith Professor of Anesthesiology, Perioperative and Pain Medicine, Icahn School of Medicine at Mount Sinai, The Mount Sinai Hospital, 1 Gustave L. Levy Place, Box 1068, New York, NY 10029-6574 (E-mail: David.reich@mountsinai.org).

J Thorac Cardiovasc Surg 2019;157:1543-4

$0022-5223 / \$ 36.00$

Copyright @ 2018 by The American Association for Thoracic Surgery

https://doi.org/10.1016/j.jtcvs.2018.09.082
}

Cost containment and value-based care are influencing cardiac surgery, with a particular focus on reducing postoperative mechanical ventilation time. The National Quality Forum includes ventilation $<24$ hours as a performance measure, ${ }^{1}$ and the Society of Thoracic Surgeons is promoting extubation within 6 hours as a quality benchmark. ${ }^{2}$ Clinical practices are adapting, with lower opioid dosing, avoidance of hypothermia, and nurse- and respiratory therapist-driven intensive care unit (ICU)-weaning protocols.

In the setting of these quality metrics, clinicians are justifiably concerned that overnight tracheal extubation is potentially unsafe. In a multicenter cohort study $(>90,000$ patients across 165 ICUs), Gershengorn and colleagues ${ }^{4}$ showed a greater rate of ICU and hospital mortality in patients undergoing overnight extubation, yet only 4 of those were cardiac surgical ICUs. In contrast, there was not a greater likelihood of reintubation, length of stay, or mortality in a smaller cohort study by Tischenkel and colleagues ${ }^{5}$ ( $80 \%$ of patients extubated overnight were from cardiac surgical units in a single hospital system).

In this issue of the Journal, Krebs and colleagues ${ }^{6}$ report on the safety of overnight extubation in 19 cardiac surgical practices in 2 states. The primary analysis found no increased risk of surgical mortality, tracheal reintubation, or composite morbidity-mortality. The strengths of the study include an impressive cohort size (39,812 extubated within 24 hours; 52.1\% between 18:00 and 06:00 hours) in a multicenter community practice setting. The subset of patients extubated between midnight (24:00) and 06:00 hours exhibited increased composite morbiditymortality (odds ratio $1.18, P=.001$ ), despite no difference in reintubation or mortality. Propensity score matching analysis would have given more assurance that the predictors of extubation were balanced among the (now 3 ) groups (06:00-18:00, 18:00-24:00, 24:00-06:00 hours) in the secondary analysis.

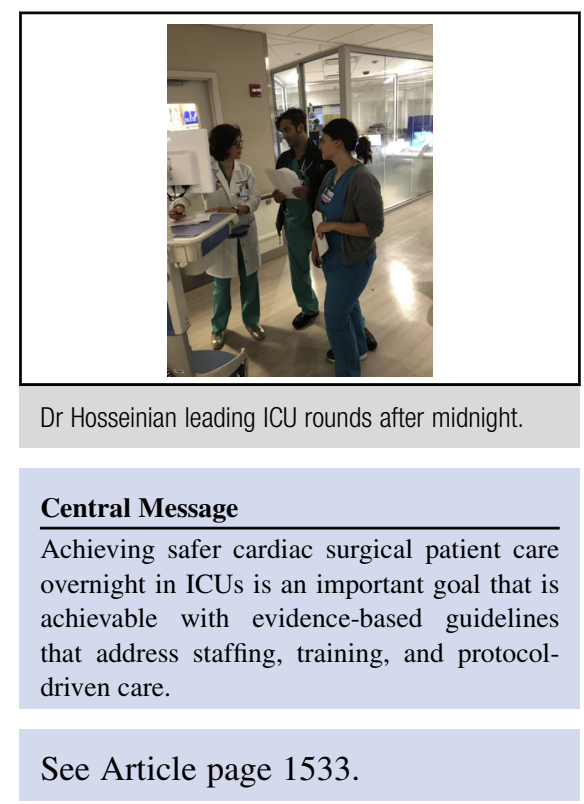

As a community-based study, lower case acuity was evident: primary nonreoperative coronary artery bypass grafting represented $>70 \%$ of procedures; $5 \%$ were reoperations; and the Society of Thoracic Surgeons predicted rate of mortality was $1.1 \%$ to $1.3 \%$. Future investigations should include additional extubation decision criteria, such as number of blood transfusions, use of inotropes, and left ventricular ejection fraction postcardiopulmonary bypass.

This study should be considered in the context of extensive variability in overnight cardiac surgical ICU practices. The safety of extubation and effective responses to deteriorating clinical status are likely influenced by ICU physician, physician extender, and nursing staffing models; staff training and competencies; and effective implementation of clinical protocols, such as enhanced recovery pathways.

The Society of Critical Care Medicine recommends inhouse certified intensivist staffing in Level 1 critical care centers, although there is no evidence of consistently improved outcomes in medical or surgical ICUs. ${ }^{7-9}$ In cardiac surgical patients, however, in-house overnight intensivist coverage was associated with reductions in postoperative mechanical ventilation, transfusions, and hospital length of stay. ${ }^{10,11}$ The authors' institution has implemented a nighttime intensivist model and a nursedriven ventilator-weaning protocol, which were associated with an improvement in the rate of extubations $<6$ hours postoperatively from $12 \%$ to $52 \%$ over several years. 
Other centers have implemented fast track protocols and improved extubation times without the addition of overnight in-house physician coverage. ${ }^{3}$ Tele-ICUs may be a more cost-effective approach to extending ICU quality and safety, although data are limited. ${ }^{12}$

We extend our congratulations to Krebs and colleagues ${ }^{6}$ for increasing the evidence base that will lead eventually to evidence-based consensus guidelines for critical care staffing, training, and protocols.

\section{References}

1. National Voluntary Consensus Standards for Cardiac Surgery. National Quality Forum. Available at: https://www.qualityforum.org. Accessed September 12, 2018.

2. STS quality webinar series: Prolonged ventilation. Early extubation and accelerated recovery protocols in cardiac surgery. Available at: https://www.sts.org/ learning-center/webinars. Accessed September 12, 2018.

3. Cove ME, Ying C, Taculod JM, Oon SE, Oh P, Kollengode R, et al. Multidisciplinary extubation protocol in cardiac surgical patients reduces ventilation time and length of stay in the intensive care unit. Ann Thorac Surg. 2016;102:28-34.

4. Gershengorn HB, Scales DC, Kramer A, Wunsch H. Association between overnight extubations and outcomes in the intensive care unit. JAMA Intern Med. 2016;176:1651-60.
5. Tischenkel BR, Gong MN, Shiloh AL, Pittignano VC, Keschner YG, Glueck JA, et al. Daytime versus nighttime extubations: a comparison of reintubation, length of stay, and mortality. J Intensive Care Med. 2016;31: $118-26$.

6. Krebs ED, Hawkins RB, Mehaffey JH, Fonner CE, Speir AM, Quader MA, et al. Is routine extubation overnight safe in cardiac surgery patients? J Thorac Cardiovasc Surg. 2019;157:1533-42.e2.

7. Wallace DJ, Angus DC, Barnato AE, Kramer AA, Kahn JM. Nighttime intensivist staffing and mortality among critically ill patients. N Engl J Med. 2012;366: 2093-101.

8. Kerlin MP, Harhay MO, Kahn JM, Halpern SD. Nighttime intensivist staffing, mortality, and limits on life support: a retrospective cohort study. Chest. 2015; $147: 951-8$

9. Kerlin MP, Small DS, Cooney E, Fuchs BD, Bellini LM, Mikkelsen ME, et al. A randomized trial of nighttime physician staffing in an intensive care unit. $N$ Engl $J$ Med. 2013;368:2201-9.

10. Kumar K, Zarychanski R, Bell DD, Manji R, Zivot J, Menkis AH, et al. Impact of 24-hour in-house intensivists on a dedicated cardiac surgery intensive care unit. Ann Thorac Surg. 2009;99:1153-61.

11. Benoit MA, Bagshaw SM, Norris CM, Zibdawi M, Chin WD, Ross DB, et al. Postoperative complications and outcomes associated with a transition to 24/7 intensivist management of cardiac surgery patients. Crit Care Med. 2017;45: 993-1000.

12. Udeh C, Udeh B, Rahman N, Canfield C, Campbell J, Hata JS. Telemedicine/virtual ICU: where are we and where are we going? Methodist Debakey Cardiovasc J. 2018;12:126-33. 